\title{
Sugars, biscuits and consumer perception: a survey of the UK biscuit market and consumers' perceptions in the context of government mandated sugar reduction and reformulation
}

\author{
G. Lever, H. Ensaff and J.B. Moore \\ School of Food Science and Nutrition, University of Leeds, Leeds, West Yorkshire, LS2 9JT, UK.
}

Over a third of children and two thirds of adults in the UK are overweight or obese ${ }^{(1)}$. Given the scientific consensus of a causal link between a high-sugar diet and obesity ${ }^{(2)}$, the UK government has outlined a sugar reduction programme to reduce sugar in widely consumed food products ${ }^{(3)}$. This includes biscuits, which are among the highest food contributors to sugar intakes in children ${ }^{(3)}$. The aims of this work were to: (i) examine the nutrient contents of biscuit products currently available in the UK; and (ii) assess consumers' perceptions and awareness of sugar ingredients, 'healthier' biscuits and sugar intake guidelines.

Nutrient and ingredient content data was collected online from the UK's second largest retailer (Sainsbury's; Kantar, 2018) from 7/ $11 / 17$ to $29 / 12 / 17$. In collaboration with Sainsbury's, a questionnaire was designed to investigate biscuit eating habits and consumers' perceptions of sugars in biscuits. Participants were recruited both online $(\mathrm{n}=311)$ via social networking, utilising Online Surveys (Jisc, Bristol, UK), and within a Sainsbury's Superstore $(\mathrm{n}=50)$. Ethics approval was granted by Faculty Research Ethics Board $(\mathrm{MEEC}$ 16-016/17/6).

Utilising a process flow decision tree, 542 unique products were categorised into eight categories: Assortments ( $\mathrm{n}=14)$, Children's $(n=25)$, Chocolate $(n=161)$, Everyday $(n=76)$, FreeFrom $(n=34)$, Healthier $(n=191)$, Bakery $(n=17)$, and Occasion $(n=24)$. The total sugar content (Fig 1A) varied enormously both within and across biscuit categories. Children's biscuits had the highest median [range] sugar content at $41 \mathrm{~g} / 100 \mathrm{~g}[20,57]$, and in all categories median sugar content was higher than the Public Health England's target of $26 \mathrm{~g} / 100 \mathrm{~g}$ (dotted line; Fig. 1A). While 'Less Sugar' was the most common attribute questionnaire respondents sought in a healthier biscuit (Fig 1B); when asked about the current UK recommendations for maximum daily sugar consumption, only $14 \%$ of online and $6 \%$ of in-store respondents could correctly specify this. Two thirds of respondents confirmed they would look for a healthier biscuit (69\% online, $59 \%$ in-store). Honey was chosen most frequently as a preferred sweetening ingredient (Fig 1C); 'healthier' and 'natural' were the most common reasons respondents gave for choosing their preferred sweeteners.
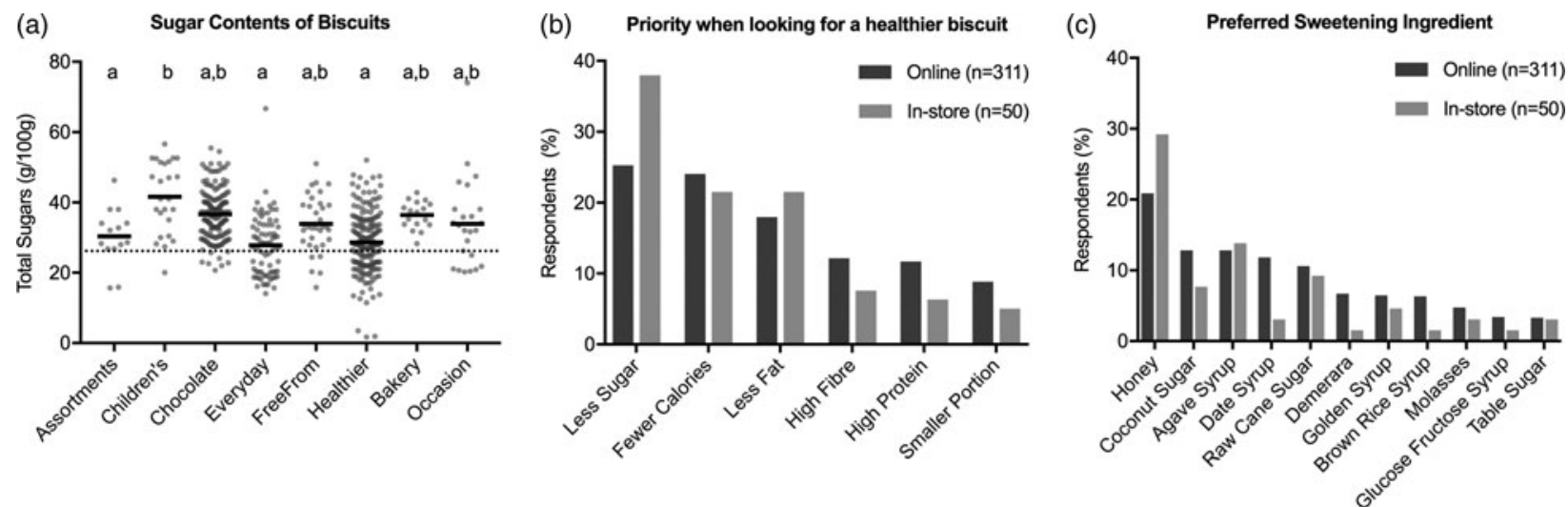

Fig. 1. Sugar contents of 542 biscuit products across eight categories (A). Respondent's priorities (B), and preferred sweeteners (C). Respondents ranked priorities $1-6$ and could choose multiple sweeteners from list of 11 .

We conclude sugar reduction and reformulation is warranted. Furthermore, consumer awareness of sugar intake guidelines and understanding of sugar ingredients should be improved.

1. Health \& Social Care Information Centre (2016) ISBN:978-1-78386-982-4 http://digital.nhs.uk/pubs/sopad17.

2. Moore JB \& Fielding BA (2016) Curr Opin Clin Nutr Metab Care 19(4), 303-9.

3. Public Health England (2017) PHE publication number: 2016677. 